International Journal of Child, Youth and Family Studies (2012) 4.1: 458-478

\title{
THE PARADOX OF THE INDIVIDUAL
}

\section{Janet Newbury}

\begin{abstract}
With the rise of neo-liberalism has come the assumption that the individual is the locus of action. Paradoxically, our heightened focus on the (generic) individual has led to universalized notions of individuality, sifting out of view the particular dimensions of experience that differentiate us from one another, rendering each (unique) individual invisible. In this article, the dynamics through which social processes are being increasingly individualized are called into question, and alternative constructions are offered. When subjectivity and ethics are reconceptualized, new paths for ethical engagement as non-unitary subjects begin to emerge. These are taken up in relation to human service practices, and some collectively-oriented approaches to practice are presented.
\end{abstract}

Keywords: contextualize, ethics, human service practices, individualism, neo-liberalism, subjectivity

Acknowledgements: I would like to thank the Community Economies Collective, all those working at what was formerly the Centre for Citizenship and Public Policy at the University of Western Sydney, and particularly Katherine Gibson, for pushing my thinking in new directions as I studied alongside them in 2012. I would also like to acknowledge the Social Sciences and Humanities Research Council for financial support, and the reviewers of this article for valuable feedback.

Janet Newbury, Ph.D. works for the Powell River Diversity Initiative, and is an instructor at the School of Child and Youth Care, University of Victoria, P.O. Box 1700, STN CSC, Victoria B.C., Canada, V8W 2Y2. E-mail: newburyj@uvic.ca. 
International Journal of Child, Youth and Family Studies (2012) 4.1: 458-478

Individualism pushed to the extreme breeds horror.

(Rosi Braidotti, 2006, p. 46)

When researchers and practitioners insist on contextualizing human service practices and attending to social conditions, this is sometimes interpreted as contrary to the overall aims of these professions. Whether coming from the perspective of a child and youth care practitioner, community worker, health care provider, mental health professional, social worker, or early childhood educator, is the bottom line of our work not the well-being of the individuals we encounter? I agree that it is. But I also maintain that attending too squarely to individuals can lead us away from this aim, in ways that are potentially damaging to them and to others. Therein lies the paradox of the individual.

In this article, I will unpack this paradox. I see great value in critically engaging with the conceptualizations that inform practice, and in the following pages will adopt a largely social constructionist approach to subjectivity in order to consider how we might engage differently with children, youth, families, and communities (see Gergen, 1994). I will begin by outlining some of the theoretical influences that have informed my developing understandings of what ethical subjectivity can look like. I will then consider the promising implications for practice that come when we allow ourselves to resist the powerful current of individualism that pulls us, and instead consider ourselves and each other to be mutually constitutive and ever-changing.

\section{Individualism: Limiting Possibilities for Ethical Subjectivity}

I would imagine most readers are quite familiar with what is meant by individualism, as it is an underlying assumption of nearly all aspects of modern society. The individual as the basis of our social systems, laws, rights, understandings of development, beliefs about success, and related practices is something that is so pervasive it feels natural. On what other basis would we organize our world? And why would we even want to consider other possibilities?

Yes, individualism is well-understood. It is the critique of individualism that could perhaps use some fleshing out. Being so deeply enmeshed in an individualistic world view in nearly all of our activities, we may spontaneously resist rustles of other possibilities. But, for me, although (admittedly) it takes extra effort to hear and make space for these resistant voices amidst the chorus of individualizing certainty, it is well worth it. The space that is being opened up by distant and disparate advocates is inviting and - once steps are taken to enter into it - can be experienced as more promising and more pragmatic than the limiting one we seem so reluctant to step outside of.

The notion that individuals exist is not what I am calling into question here. What is of concern is the "extent to which people ... address persons as causes of behaviour and thereby 'individualize' them” (Nollman \& Strasser, 2007, p. 85). Nollman and Strasser remind us to take note "that this process is inherently social and interactive from the beginning" (p. 85). Although this kind of decontextualized individual agency is now a taken-for-granted assumption for many, it is a relatively recent understanding of the subject, and has been linked with the political discourse of neo-liberalism (Braidotti, 2006; Carmody \& Carrington, 2000; Howard, 2007; 
International Journal of Child, Youth and Family Studies (2012) 4.1: 458-478

Teghtsoonian, 2004; Winegard \& Winegard, 2011). According to Howard (2007), "[i]n neoliberalism, individuals are interpreted as rational and self-interested beings who seek material advancement, while rejecting public or social intervention into their lives. This paradigm equates individuality with freedom” (p. 3).

Taking hold during the Enlightenment (Taylor, 2007) and strengthening with neoliberalism (Braidotti, 2006), the idea of individuals as discrete, bounded beings who are selfdetermined and self-serving can thus be understood not as a reflection of empirical reality, but as a construction that serves particular functions (Gergen, 1994). Importantly, calling the individual a construction does not mean there are no material effects or that we - as subjects who understand ourselves largely in these terms - do not have experiences on their basis. On the contrary, it is the fact that such a construction serves the "purpose of capitalist industrial economy" at the expense of the well-being of citizens and the planet that causes such concern for many of these thinkers (Braidotti, 2006, p. 244).

In particular, Braidotti (2006) notes two core objections to the unitary subject of individualism: its anthropocentrism and its universalism. In relation to the former, she argues first that this is a representation that contradicts our experiences as "embodied and embedded entities” (p. 132). She and others (see Abram, 1996; Gergen, 2009; Merleau-Ponty, 1964) note that our physical and psychic selves are constituted via ongoing relations with other human and non-human entities. At a minimum, we consume them, and they us. There is, from this perspective, no in-between space, but only a series of simultaneous and constant "transpositions" from one mode of being to another. If this experience of being relationally constituted is another plausible subjective construction, then what are the implications of "individualizing" these dynamic processes? That is, what happens when we distill their meaning down to the level of the individual actor, and respond to them as such? I will return to this question shortly.

Braidotti's (2006) second objection to the construction of the subject as a unitary individual is its universalism. Her concern is, in part, captured by Derrida (1995), who suggests that when the focus is placed on the "generic" individual, the "unique" individual can disappear completely. Derrida's call was for a deep attentiveness to the particulars of each situation or individual or encounter in the pursuit of more just ways of engaging with each other and the world. Levinas (1982/2003), too, refuses to universalize the subject, and is instead committed to what happens in each unique encounter with an unknowable "other". Braidotti (2006) shares these concerns, and is explicit in her extension of them to the non-human world. She says:

A sustainable ethics for a non-unitary subject proposes an enlarged sense of interconnection between self and others, including the non-human or "earth" others, by removing the obstacle of self-centred individualism. This ... implies a new way of combining self-interests with the well-being of an enlarged sense of community, which includes one's territorial or environmental interconnections. (p. 35)

The enlarged sense of community to which she appeals is not about extending universalized notions of the good and ethical more broadly. It is about recognizing our unique 
International Journal of Child, Youth and Family Studies (2012) 4.1: 458-478

and particular encounters with "others" that exist outside of what might currently comprise our conceptual community.

An important critique of Braidotti's work, however, comes from critical race scholars who observe that while she acknowledges we are "embodied and embedded" (p. 132), she seems to downplay the disparities of experiences among us when it comes to the effects of our embodiment. Radhika Mohanram (1999), for example, makes an important distinction between the intellectual concept of nomadic subjectivity advocated by Braidotti and the very real barriers to the realization of this experience for some people and not others. To illustrate her point, Mohanram observes:

[A] lot of black women cannot be perceived beyond the body. The literal aspect of nomadism - the ease of and the right to mobility - is reserved for women with strong passports. Women with weak passports are normally confined within their borders. (p. 82)

Mohanram (1999) notes that although Braidotti strives for fluidity of the subject, she nonetheless "disregards that at some level the material reality of the body also fixes it racially, culturally, and socially” (p. 82).

Although perhaps not sufficiently addressed in her theories of subjectivity, Braidotti (2006) acknowledges the inequities at play in the current world order and the fact that vulnerability is always in play within power relations. She observes that "the difference between the winners and the losers of the present economic world order is that winners only put their money on the line, while the losers risk their bodies” (p. 53). Braidotti's position, however, is that in fact all bodies are on the line already, despite current dynamics that may obscure this fact. She invites us all to embrace the reality of our vulnerability in order to set the stage for different ways of conceptualizing the subject such that interconnectedness might better be recognized and embraced, which might in turn flatten the inequities to which Mohanram draws our attention. In this sense, Braidotti's notion of non-unitary subjectivity might be better understood as a projection of possibilities, rather than a description of current arrangements.

To illustrate the shift Braidotti (2006) is inviting - and to allow for a more elaborate extension of it to better address the diversity among even human experiences - consider human rights. Within neo-liberal individualism, rights can be universalized, replicated, and extended; indeed, they were constructed with that in mind. However, Farmer (2005) suggests that universally "applying” rights enables us to overlook inequities that precede them, using them as a way to treat everyone "the same", rather than working towards more equitable conditions (which may realistically require preferential treatment of some). In this way, rights can be taken up in ways that maintain the status quo, rather than alter it. Todd (2008) agrees that conceiving of the subject in universal terms can lead to a counterproductive use of the concept of rights in that it restricts, rather than enhances, freedoms. She asserts that "freedom, which is so central to rights, ... exists in the I's capacity to respond to the Other” (p. 63). Discourses of rights that are constructed on the basis of universal notions of the individual subject limit the potential of actual individuals to experience the freedom that one might think would come via rights. Instead, the 
International Journal of Child, Youth and Family Studies (2012) 4.1: 458-478

unique individual disappears amidst the abstractions. Todd promotes a reworking of the concept of rights so that they can be contextualized, responded to, and creatively engaged with. This, she argues, would facilitate freedom for actual - not universal - subjects.

The example of rights illustrates how individualizing the subject leads to anthropocentric and universalized notions of subjectivity. This, in turn, can create constrained conditions not only for present-day individuals, but also for those who inherit our increasingly individually-oriented institutions and practices.

\section{The Trouble with Individualization}

A moment ago I posed the question: What happens when we distill the meaning of dynamic social processes down to the level of the individual actor, and respond to them as such? This process can serve as a definition for what I am referring to when I use the term "individualize". It is a verb, which describes the way we conceptually locate agency within the construction of the individual subject, largely eliminating social conditions from consideration when it comes to why things happen, and how things can happen differently. I acknowledge that the term is sometimes used differently by others (see, for example, Yeatman, Dowsett, Fine, \& Gursansky, 2009) to describe more client-centred approaches to practice. I appreciate these ideas and see value in client-centred practice. But I am using the term "individualize” to help focus my attention on the process by which individualism becomes normalized. I believe that by focusing on the process, the fact that this norm is constructed through certain discursive practices can be highlighted. This awareness can enable us to consider other potential processes, which might lead us toward more relational and contextual conceptions of the subject. These new conceptions, in turn, can significantly inform human service practices, which involve encounters with "other" subjects.

I am not alone. Others have taken up the term individualization similarly in various areas of study and practice, and have demonstrated how doing so can make space for different ways of engaging. For instance, Carmody and Carrington (2000) challenge the reductionist process of individualization in relation to the prevention of rape and other sexual violence. They say:

While we recognise that responsibilising victims and individualising offenders is consistent with wider global shifts in social policy calling upon individuals to manage their own risk, we argue that the increasing reliance on such neo-liberal social policy is especially problematic in preventing rape. (p. 341)

Rather than locating problems and solutions within individual offenders (and victims), Carmody and Carrington's approach to sexual violence prevention looks at how to cultivate ethical sexual subjects. They resist the notion of men as "natural" predators and women as "natural" victims in order to provide more options for both men and women when it comes to creating a culture of ethical sexual encounters. Options for men open up beyond "getting" sex, and options for women beyond "resisting" violation. Instead, both are able to engage in negotiations around meaningful and pleasurable sex. This also helps move outside of the heteronormative discourses that so often accompany violence prevention work, and opens up a 
multitude of healthy sexual possibilities. The focus of this work is thus on "how" sex is negotiated, not on "what" sex is.

Similarly, Richardson and Reynolds (2012) resist "the individualization of injustice and the privatization of pain” (p. 6) in the context of community work. They argue that discursively placing the locus of change inside individuals is, in fact, one of the means by which injustices and pain persist because it prevents us from addressing the conditions which, in part, generate these experiences. As a concrete example, they "are critical of the individualization of 'burnout' and the limits of 'self-care' which lays the burden of an unjust society on the backs of individual workers” (p. 7). As an alternative metaphor, Reynolds (2011) has suggested that community workers do not burn out, but they are "blown up" by the injustices they experience through isolation, unsupportive working conditions, and the spiritual pain that comes when workplace responsibilities (such as surveillance, diagnosis, and documentation) contradict an underlying ethic of solidarity with clients. Resisting this requires more than "self-care"; it can involve the creation of communities of support across various disciplinary or other identity lines (see Denborough, 2008). When workers and other community members collaborate and support each other (rather than, as is so often the case, compete with each other for "scarce resources"), conditions change, which in turn effectively diminishes the experience of being "blown up".

What both of these examples highlight is the ethical requirement to extend notions of subjectivity beyond the individual so that more possibilities for change can be rendered intelligible. Individual workers and individual service recipients will never be able to effectively respond to the complex dynamics in which both exist in isolation. As long as the responsibility for change lies on the shoulders of conceptually disconnected individuals, we will find ourselves coming up short when trying to provide real and hopeful alternatives for those who are struggling. But perhaps if we could conceive of the subject in terms that better reflect our mutuality, our understandings of agency will also be transformed. It is to some of these possibilities that I will now turn.

\section{Alternative Constructions}

If not as an individual, then how might the subject be conceptualized? Drawing from a range of relational theorists (including Buber, 1923/1970; Levinas, 1982/2003; and Foucault, 1972), contemporary thinkers offer alternative constructions of the subject that contribute to rich possibilities for ethical engagement. While the concepts and vocabularies used by these theorists and activists differ slightly, I experience their ideas as mutually supportive. Indeed, there seems to be a collective (albeit amorphous and diverse) conceptual shift away from atomistic notions of the individual taking place. All of the contributors from whom I now draw are working towards pulling into our consciousness additional elements of our being: those which are obscured by the individualizing processes described above.

\section{A relational subject}

The western conception of the individual self has run its course. The view of the private self as the source of art and literature, practical decisions, moral deliberation, 
International Journal of Child, Youth and Family Studies (2012) 4.1: 458-478

emotional activity, and the like is no longer viable - not only on conceptual grounds but in terms of the societal patterns it invites. (Gergen, 1994, p. 181)

Kenneth Gergen (1994, 1999, 2009) has been a central figure in the conceptual shift of the subject from an individualistic entity to a dynamic, relational construction. As the above quote indicates, this shift is seen as necessary not only because an individualistic understanding of the subject inadequately represents our complex experiences of being, but also because it limits possibilities for ways of engaging in and enacting a society worth living in. Understanding the subject as a relational construction, on the other hand, allows for more dimensions of experience to be taken into consideration when it comes to how decisions are made, what kinds of behaviours are exhibited, and how we might go about pursuing certain goals. Indeed, the “individualization" of what Gergen (1994) opts to represent as relational processes "sustains a cultural system of individual blame” (p. 110). When this occurs, the only possible route for change seems to come through individual action. However, when the relational view of the subject is embraced, doors open when it comes to possibilities, because - as Braidotti (2006) says -“"we' are in this together” (p. 36, emphasis in original). (Braidotti seeks to emphasize the contested nature of the terms 'we' and this that necessarily comes about when subjects are not understood as static, singular entities).

A relational subject is one that is constituted by and constitutes those with whom it relates. Thus, echoing the voice of Buber (1923/1970), there is no "I" outside of the relation; the "I" continues to grow and morph, depending on the relationships in which it finds itself. This disperses the onus for change, of course, onto all of us.

\section{A situated subject}

Although often understood in terms of interpersonal dynamics, "relationships” need not be interpreted anthropocentrically. The relational perspective extends (or at least can extend) to all human and non-human interactions. For example, drawing from Merleau-Ponty, Abram (1996) calls attention to the ways even our physical selves develop in response to the material world in which we live. Butler (2004) emphasizes corporeal vulnerability as an important dimension of relational subjectivity, and one that can help cultivate a shared sense of responsibility - even on a global level. And Rose (2008a) argues that we need new "ways of understanding ourselves from within a relational ontology that is also an ecology" (p. 163). Clarke (2005) facilitates this conceptual shift by speaking of "the situation" as the unit of analysis, rather than an individual or its "context”. The situation, according to Clarke, is inclusive of all human and non-human dimensions of what is happening - including among them temporal, spatial, discursive, and relational dynamics. This means the subject can never be removed and understood in isolation, but must be seen as always "embodied and embedded" (Braidotti, 2006, p. 132).

By conceptualizing the subject as situated, the concept of an "in-between" space that exists somewhere outside of the "self" or the "other" vanishes. Rather than asking questions about that space, then, Rose (2008b) invites us to consider this: 
How would our questions be framed if we turned the focus away from the in-between space, whether atomistic or founded in connectivity and entanglement, in order to ask questions about the relational field of connectivity within which selves are entangled? ... To focus on the field we have to lift our eyes from the page and turn them toward the living world. We are invited to think about pattern rather than space, and this means thinking about time, rhythms, organization, and the interplay of difference and similarity. (p. 110, emphasis added)

Here, Rose is inviting an experiential understanding of subjectivity - one that relies on multiple senses and occurs in time and space. Abram (1996) has encouraged us in a similar direction, reminding us both of the qualitative richness that comes when we allow more dimensions of experience to inform our imaginations and the quantitative expansion of possibilities for new forms of action that can be embraced by a situated subject. All of these authors insist that the opportunities that present themselves with this reconceptualization can support us in forging more ethical paths, as the emphasis is on dynamics, rather than states of being. When we cease to see ourselves as isolated from one another and instead see ourselves as always engaged in patterns of relating, then our responsibility to one another is heightened. This is significant for me, and is why I do not want to overlook the paradox of the individual within human service practices, but believe there may be value in wading further into it.

\section{A nomadic non-unitary subject}

Embracing both the relatedness and the situatedness of this alternatively conceptualized subject, Braidotti (2006) proposes “a nomadic eco-philosophy of multiple belongings” (p. 35). This, she suggests, can offer a richer foundation for ethical engagement in an uncertain world. The subject she envisions is one that can better respond to the complicated world we have created. In addition to viewing the subject as relationally constituted and situationally embedded, then, she posits that it is also non-unitary and nomadic. By doing so she aims to take into consideration the multiple belongings and constant flows of transformation that characterize the subject of the 21st century. In very literal ways - with things such as genetically modified foods; organ transplants from other species; globalized travel, communication, and trade; online communities; sexual realignments; cyborg technologies; and transnational identities - we can no longer identify ourselves in unitary terms. To conceptualize the subject as an individual and to privilege the concept of independence in the face of such realities begins to seem absurd.

Braidotti (2006) argues, however, that deliberately incorporating these complexities of life into conceptualizations of the subject can enable us to imagine a life for which the "I" is not the centre. And this, she says "is actually a sobering and instructive process. This is the very start for an ethics of sustainability that aims at shifting the focus towards ... positivity ...” (p. 40).

\section{Ethical Ways of Being}

Abram (1996) points out that generalist notions of ethical conduct are also a product of current cultural realities. To speak of right and wrong in general terms without attaching them to particular events that occur in a time and a place would be meaningless within the traditional 
context of the Navajo, for instance. For them, processes of discernment would necessarily be informed by particular contextual realities, not by universalized concepts such as rights and laws. As described in the previous discussion, the individualization of complex social phenomena has, on the one hand, meant that our gaze shrinks to the level of the individual at the expense of broader political, cultural, and economic considerations. At the same time, by decontextualizing individual experiences, we universalize our understandings of the individual. In this way, the paradox of the individual can be acutely felt.

But when alternative conceptualizations of the subject are embraced, this tendency to universalize has to be revisited. If the subject is not understood as a discrete and unembedded individual, but rather as relational, situated, nomadic, and non-unitary, then a universalized approach to how to ethically engage with each other (including non-human "others”) ceases to make sense. The question then becomes: On what basis can ethical conduct be pursued? This is significant when it comes to human service practices, which - as stated previously - involve intimate encounters with unknowable others. If my interest is in supporting the well-being of children and families, for instance, how can I ethically engage in my practice if I conceptualize the subject in non-unitary and nomadic terms? Reconceptualizing ethics is a significant step towards answering this question.

\section{Ethics of disruption}

If we, as subjects, are amorphous and continuously being constituted by (and constituting) that with which we relate, then everything we do is potentially disruptive. Each small action - including the choice not to act - will alter other non-unitary subjects in unpredictable ways. Deborah Bird Rose (2008a) embraces this possibility, and uses it to inform what she conceptualizes as an ethics of disruption. Our responsibility lies not in whether we engage - which is something we clearly cannot opt out of - but how. By being intentionally disruptive, we can actively resist the modernist tendency to nail things down and eliminate mystery. The word "intentionally" is key here; of course we will disrupt, but an ethic of disruption requires close attention to how we do it.

Rose (2008a) notes that given the current cultural commitment to certainty and singularity, "wild” and disruptive concepts and experiences seem almost inevitably to be "tamed" despite themselves. She even remarks on the possibility that she unwittingly does this within her own writing when she says:

I worry about whether my words really are sustaining the respect for the awesome which so characterized my Aboriginal teachers' approach to the living world, or whether my words are opening gaps wherein the awesome can be tamed. Probably they do both, and perhaps this is one of the great tensions about wanting both to respect difference and to communicate across difference: the attempt opens possibilities for both disruption and domestication. (p. 158)

An ethic of disruption, then, is deeply reflexive. It attends not only to what an action does or even to its consequences, but to what it continues doing once it has engaged with, been taken 
up by, and inevitably been altered by the nomadic subjects with whom it interacts. This means responsibility does not start and stop with the individual. An ethic of disruption knows no such boundaries.

\section{An ethic of sustainability}

Above, Braidotti (2006) was quoted as saying the thought of a life without "me" at the centre is "the very start for an ethics of sustainability" (p. 40). Taking the non-unitary subject as a starting place, the codependence of different species (and entities) not only becomes conceivable, it "reiterates the importance of grounded, situated and very specific and hence accountable perspectives" (p. 123). This does not mean "anything goes", as is so often the response. It simply means that judgement cannot come without considering the particular dimensions of each unique instance. Since the world is constantly undergoing transitions big and small, judgement can only come after the fact, not before.

The reason "sustainability" is the concept through which this ethic is realized, is because of both its temporal and affirmative nature. In terms of its temporal nature, an ethic of sustainability draws our attention to living time and space. It requires that we think beyond ourselves and beyond the now - in all directions (past, present, future, and laterally). But it also provides openings for thinking differently about what is possible in the now, as we "think the unthinkable and imagine the unimaginable” (Braidotti, 2006, p. 201). In this way, the future can inform the present, bringing about the possibility of new realities. In this sense, its affirmative nature is also explicated. When thinking in terms of sustainability, creative or generative power is activated. Particularly since the subject is understood as non-unitary, "sustaining” anything automatically implies constant change. In this sense, an ethic of sustainability is creative and affirmative; it involves the deliberate, ongoing, and responsive cultivation of that which is being sustained. Thus, according to Braidotti (2006), "ethics is a matter of experimentation, not of control by social techniques of alienation” (p. 214).

Absorbing the ethic of disruption and the ethic of sustainability together, it becomes clear that from the perspective of the nomadic subject, ethics is understood as a process which is highly reflexive.

\section{An ethic of solidarity}

From this perspective, ethics can also be understood as a process that is shared. If the individual subject is not an adequate conceptualization to encompass our complex subjective experiences, then individual responsibility will not be adequate to describe how ethics can be enacted. Carmody (2005) offers ways of collectivizing ethical conduct, which shift the emphasis from rigid "codes” of behaviour to processes of negotiation. Drawing largely from Foucault's notion of "the care of the self", Carmody suggests "the care of the self is intimately linked with ethics and that ethics is the considered form that freedom takes when it is informed by reflection" (p. 469). When subjectivity is understood in the relational terms described above, then ethics cannot be an individual exercise or achievement. Instead it is a negotiation, which moves among care of the self, care of the other, and reflection. And of course this is necessarily ongoing, since 
the mutually constitutive nature of "self" and "other" render the two terms almost moot. Ethics is thus collectivized.

Richardson and Reynolds (2012) also promote a collectivized notion of ethics, which they articulate as an ethic of solidarity, described as follows:

Solidarity speaks to the interconnections of our collective movements towards social justice, and in resisting oppression. Profoundly relational understandings of solidarity have been credited to different Indigenous Elders. Lily Walker, an Australian Aboriginal women's leader, describes solidarity beautifully while speaking to nonAboriginal activists at a land rights protest: "If you come here to help me, then you are wasting your time. But if you come here because your liberation is bound up in mine, then let us begin" (Walker cited in Sinclair, n.d.). (p. 9)

In this sense, an ethic of solidarity requires an understanding that all actions are disruptive, and we have an ethical obligation to be deliberate about how we disrupt. It also embraces the multi-directional nature of influence among non-unitary subjects, which means we cannot exert influence in predictable directions as individuals. Rather, we must engage in shared efforts through partnerships of mutual negotiation. Stated differently by Rose (2008a), "one part of the whole, say the human part, cannot effectively engineer the whole, because the whole will always be greater than the part can understand” (p. 159). An ethic of solidarity takes this as a starting place and recognizes the transformative potential of engaging as a part of the (never fully known) whole.

This is therefore not about creating tight-knit, exclusive communities of support that rely on shared identities. Rather - embracing the nomadic subject - an ethic of solidarity accepts the likelihood that allegiances will also always be in motion. Richardson and Reynolds (2012) explain:

Our solidarity can be imperfect and fluid; we're not invested in perfect relationships of unity or cohesion. We look for points of connection, and spaces where we can back each other up authentically. ... Our impermanent allegiances are based on situational and timely concerns that bring people together for moments of sacred collision and cooperation. (p. 9)

An ethic that is based on disruption, sustainability, and solidarity is an ethic that can engage non-unitary subjects. How might this differently inform the way human service practices are taken up?

\section{Taking up and Travelling with these Ideas}

Braidotti (2006) surmises that "a non-unitary vision of the subject, combined with an ethic of sustainability, allows us to bypass the habit that pathologizes self-destructive practices ... It also generates new and more complex forms of compassion or deeply shared affinity in others” (p. 223). If this is the case, then the implications of these ideas regarding 
how human service professionals engage in practice may be profound. At times, highly individualized practices may be precisely what are called for in order to work in the best interest of actual subjects. I believe the conceptualizations of subjectivity and ethics articulated above can, in fact, help us when discerning when that is the case. This is not about privileging the collective over the individual (or vice versa), it is about understanding them as one and the same.

So for example, although Carmody's (2005) work involves the cultivation of ethical sexual subjects, there are obviously times when unethical sexual behaviour takes place. If someone has been sexually violent or has experienced sexual violence, then attending to that unique individual's needs is of utmost importance. This does not contradict notions of nonunitary subjectivity or ethics of solidarity. In fact, such relational concepts can heighten our sense of responsibility, and our ability to respond, when we encounter others in such situations. This perspective allows for the fact that the cultural shifts towards which Carmody and others are striving involve developing different ways of engaging as and with individuals.

That said, if we resist the tendency to completely individualize acts of sexual violence, but understand them also as significant manifestations of misogynistic dimensions of our cultural and political reality, then dynamic, shared notions of subjectivity and ethics can add new (not replace existing) dimensions of responsibility in such situations. In this way, we can take up and travel with the ideas explored thus far in order to resist the tendency to individualize our understandings of why things happen, and how they can happen differently. Doing so may help us develop collectively-oriented practices which can contribute to the creation of conditions in which actual individuals' desires, gifts, and needs can more readily surface and be engaged with in all their particularity.

\section{Prevention}

Prevention is often developed in highly individualized terms. Sexual violence prevention, for instance, overwhelmingly involves teaching girls to "avoid” risky situations, and (to a lesser extent) working with offenders after they have committed a violent act (Carmody \& Carrington, 2000). Suicide prevention often places the onus on friends and family of potentially "suicidal" individuals to recognize and respond to what are understood as indicators (Morris \& White, 2010). Addiction prevention efforts often centre teaching about drugs and encouraging right choices, largely overlooking “social determinants of health” (Saul, 2005, p. 6; see also Newbury \& Hoskins, 2008). Such individualized approaches to prevention do not achieve great rates of success, and it has been argued that this is the case because they overlook the dynamics that contribute to the prevalence of the experiences prevention efforts aim to address (see Kwee, 2007; Neuhaus, 1993; and Truan, 1993). Refusing to individualize these phenomena, what might be done differently in the face of painful experiences? How can prevention efforts be informed by notions of non-unitary subjectivity and an ethic of solidarity?

According to Carmody (2003), the prevention of sexual violence becomes more achievable when we dedicate ourselves to "promoting its opposite: the inculcation of ethical sexual practices" (p. 200). This is an effective illustration of the "affirmative” nature of 
Braidotti's (2006) ethic of sustainability. By engaging people - of various ages, genders, and sexual orientations - in processes through which they can collectively explore what ethical sexuality involves, the conditions in which sexual violence takes place are dramatically altered. Her work with young people, the military, football teams, and others, has thus far indicated that when people learn to negotiate sexuality, the burden of prevention becomes collectivized, leading to very promising (and sustaining) outcomes (M. Carmody, personal communication, March 7, 2012). This collective work contributes to ontological shifts on individual levels, as well as cultural shifts within, for instance, schools, organizations, and sports teams. In this way, the subject cannot be understood in discrete, unembedded terms, as she or he is changed by and in turn changes through relating.

Relational work in the fields of suicide prevention (Kral, Wiebe, Nisbet, Dallas, \& Okalik, 2009; Morris \& White, 2010) and addiction prevention (Newbury \& Hoskins, 2010) offers similar findings. When individual pathology is the central focus of prevention efforts, relapse and further suffering can follow. But when collectively cultivating conditions that foster well-being is prioritized, the pain and isolation that may lead individuals towards either suicide or addiction can be diminished. When people are supported to experience less isolation and stigmatization, experiences with violence (Bostock, Plumpton, \& Pratt, 2009), rates of suicide (Haas et al., 2011), and the prevalence of addiction (Truan, 1993) can be reduced. Thus pursuits for just and healthy conditions on a collective level can be deeply meaningful when working to prevent individual suffering.

Prevention from this perspective may take many forms: A community resource centre that fosters informal supportive relationships can serve important preventive functions; a community radio which gives people opportunities to engage in public matters, learn skills, and develop a sense of belonging can also function preventively. A community garden that nourishes people, provides a sense of responsibility, and can even be the source of income can be a very significant preventive measure. These shared initiatives do not overlook the individual; they simply refuse to individualize their pain. By fostering conditions of inclusion, support, and belonging - which are well known to enhance well-being for adults and children alike (McKnight, 1995) - actual individuals can chart the space in which they might shine.

\section{Community development}

These ideas support the role of community development as a potentially significant component of human service practices. Whereas such practices are often primarily identified in terms of interpersonal intervention, there is a strong case here for intervention of a different kind. If subjects are mutually constitutive and locally situated, and if ethics involves disrupting existing patterns that contribute to pain and suffering with an emphasis on fostering solidarity, then it stands to reason that meaningful intervention can take place at a number of levels.

For instance, Albanese (2010) notes how our current neo-liberal climate is contributing to the development of increasingly individualized understandings of such a complex phenomenon as child poverty. There has been a shift in public discourse towards increasingly targeted interventions that focus on so-called at-risk populations. Using the term "at risk" as a descriptor 
of certain groups decontextualizes their struggles, and shifts responsibility to individuals when it comes to addressing what is clearly a global economic and political issue. Similarly, Teghtsoonian (2004) observes patterns of increased depression, particularly among women, that coincide with the rise in neo-liberal policies and practices. She observes that even though isolation and stress are experienced as a result of highly social processes, they are increasingly interpreted as individual problems (i.e., individualized), which increases the burden on individuals when it comes to altering these patterns (providing limited options such as medication and counselling).

In relation to both child poverty and women's depression, our altered conceptualizations of the subject and ethics can make space for community-based avenues through which positive change can be pursued. Asset-Based Community Development (Kretzmann \& McKnight, 1997) is one approach to community change that builds on the affirmative possibilities highlighted by Braidotti's (2006) ethic of sustainability. Rather than beginning with needs (i.e., deficits), this is an approach to change that takes existing assets (i.e., strengths) as a starting place. By identifying assets, the resources with which they can be extended are mobilized, thus addressing needs indirectly by cultivating their opposite (as suggested above by Carmody). Such an approach also incorporates Rose's (2008a) reminder that the whole is greater than the sum of its parts. Whereas individually, all members of a community will have some strengths with which alternatives can be pursued, taken together their assets will always be greater and can be more feasibly employed.

Asset-Based Community Development can be engaged with in any number of ways. One example of how it has been taken up is through the work of the Community Economies Collective. This is an international group of academic and community activists who have opened up the concept of economy to include all the diverse activities that fit within the definition of "the production and distribution of goods and services" (Healy, 2010, p. 500). They intentionally highlight "the interdependence of all who produce, appropriate, distribute and consume in society” (Cameron \& Gibson-Graham, 2003, p. 153). Doing so allows the assets that children and women contribute to a community to become visible, valued, and supported.

To see how this can play out, consider the hypothetical case of a working mother who is struggling with anxiety and depression as a result of feeling stressed and isolated. If she chooses to seek support, the identification of her unique individual strengths may be an effective starting place (MacArthur, Rawana, \& Brownlee, 2011). But stopping there can still individualize her experience, and the responsibility for mobilizing those strengths remains largely on her shoulders. If, instead, she is understood as a relational, situated, and non-unitary subject and an ethic of solidarity is embraced, then a more dynamic and relational approach to change can come to light. If her personal strengths are considered along with other resources and assets around her, new possibilities can emerge, leading eventually to the construction of less constraining conditions. Her stress and isolation could in turn be lessened, thus alleviating her experiences of anxiety and depression.

A community economies approach to this situation could enhance the cultivation of concrete supports and opportunities for connection for this woman. From this perspective, things like school lunch programs, government-subsidized childcare or an informal childcare collective, 
universal parental leaves, higher minimum wages, and other initiatives that sustain all citizens (and that particularly serve preventive functions for those currently deemed “at risk") are accounted for as assets to the community economy, not liabilities. Such community-level changes could significantly lessen this working mother's sense of isolation and increase her ability to find meaningful and practical supports in her community, both of which would have positive implications for the anxiety and depression she is experiencing.

If the well-being of the people we encounter is the bottom line of the various human service professions, then widening our gaze to the level of the community is crucial. Any approach that is decontextualized misses significant opportunities for making meaningful changes within the very conditions where children and families live, and runs the risk of increasing the burden of responsibility on already overwhelmed individuals. In this way, interventions that are collective in nature can be seen to have profound impacts at the individual level.

Returning to the earlier discussion of ethics - which involve disruption, sustainability, and solidarity - this new understanding of economy is a way of bringing situated and reflexive approaches to discernment into practice. As Cameron and Gibson-Graham (2003) point out, "[i]n the diverse economy we ... are forced to inquire into the specific conditions of any economic activity before we can advocate or oppose it” (p. 153). Thus, community development from this more contextualized perspective requires ongoing deliberations, not up-front decision-making. As such, it is something that invites engagement among non-unitary, relational subjects. And as Doherty and Carroll (2007) suggest, we need to "think of ourselves as citizens, not just providers, as people engaged in partnerships with other citizens to tackle public problems” (p. 225).

\section{Policy}

But how does such collective deliberation take place? If this approach embraces a "dual focus on individual change and social reform” (Malekoff, 2010, p. 6), then how are (relationallyconstituted, always situated) individual subjects to engage meaningfully in such collective processes? How can an ethic of solidarity be enacted at a community level or even a policy level? Carson and Lubensky (2010) observe that:

a healthy democracy is marked by willing and active public participation. It may end with voting, but the public should also be involved from the start in framing the choice ideas. In addition to attracting interested public participants, evidence is required that the deliberative nature of the engagement is held up to democratic ideals. But, ... this is quite difficult to operationalize. (p. 45)

In this regard, dynamic conceptualizations of both subjectivity and ethics are helpful, in that they can serve as reminders that this cannot be about "finding" structures that work and institutionalizing them in any fixed or final way (Sen, 2009). There needs to be a way to account for the relational and situated nature of what is being called for here, and a way of folding in 
International Journal of Child, Youth and Family Studies (2012) 4.1: 458-478

reflexive processes that can facilitate the form of ethical engagement that is required when deliberation is to take place after (not before) the fact. How can this be realized?

Human service practitioners can be considered to be well positioned, in some respects, to facilitate such relational ways of engaging with matters of policy. For instance, although Mitchell (2011) notes a "systemic resistance" to meaningful partnerships, particularly when it comes to youth (p. 521), he insists that it is the responsibility of those who work with youth to persevere in altering the status quo by reconceptualizing youth as competent - and engaging them as such. This means resisting a patronizing model of service which is hierarchically organized and instead recognizing the tremendous societal and personal benefits that come with meaningful youth participation in social action such as, in Mitchell's case, health policy development.

As another example, Malekoff (2010) strategically uses group work in order to engage in advocacy in his social work practice. He reports that engaging youth and adults alike as advocates when it comes to the matters that affect them most is a significant avenue through which both individual and social change can occur. This can involve a wide range of practices, including, as Malekoff notes:

[d]emystifying the issues and educating group members (staff, board, community, and consumer/clients), creating talking points and protest letter templates for communicating with legislators and public officials, and developing a story to tell that would make the issues interesting and important to people that needed to be reached. (p. 5)

Importantly, although he works in the field of social work, this is very much a collaborative approach to practice, where efforts are engaged in with clients, not on their behalf. This kind of advocacy can have profound impacts on many levels simultaneously, one of which is the attitudinal shift among policy-makers themselves when it comes to seeing citizens as agents in their own right, rather than simply recipients of services.

Such shifts in the collective imagination can in turn enable institutions to be differently organized. This sets the stage for the possibility of public participation (not just consultation) at various stages of decision-making (Lenihan, 2012). The contextualized approach being advocated here requires that the unique circumstance people are facing at particular moments in time need to make their way into policy discussions. Since ethical discernment cannot take place before the fact, then constant negotiation and reflection needs to be part of policy-making processes.

Lyn Carson (2011) offers some ways this can be better incorporated into existing democratic systems. She points out that in order for collective processes to be effective, information cannot travel in only one direction. It is not enough for governments to disperse information to the public, nor is it enough for individual citizens to simply present their perspectives to government. It is important for all parties to be exposed to the diverse range of perspectives on a particular issue and to have opportunities for dialogue with each other. It is 
International Journal of Child, Youth and Family Studies (2012) 4.1: 458-478

only with such a process that we can shift from rigid identity positions around public matters and allow for our nomadic subjectivity to be engaged by the myriad realities at play.

Carson outlines, for example, how to run a World Café dialogue, and notes that it can serve as a model for collective deliberation in which "participants [do] not have a problem shifting their focus from atomized self to social community” (p. 13). She emphasizes the importance of having a diverse group of participants, including people who are in decisionmaking positions as well as those who are not. This enhances the likelihood of cross-pollination of ideas and increases the transformative potential of the process. Such a process acknowledges the concrete lived experiences people have as "individuals", while at the same time embracing our non-unitary subjectivity and taking a solidarity approach to ethical engagement. Making facilitated public deliberation processes an integral part of public life means individuals need not bear the burden for change in isolation, but subjects (in all our multiplicity) do bear responsibility when it comes to engaging in these practices. Public deliberation can be one avenue for collectivizing our experiences - and the means by which new experiences can become possible.

\section{Contextualizing Care}

I began by noting that sometimes efforts to contextualize human service practices are seen as a step away from prioritizing the well-being of individuals. I can see how it might be seen as such, and I do not want to argue that thinking contextually is somehow a "way out". As Braidotti (2006) advises that, "given the complexity and paradoxes of our times, there cannot be only one political frontline or precise strategy" (p. 134). Nothing is invulnerable to corruption, so vigilance is needed, regardless of the approach taken. That said, I do maintain that the tendency to focus our gaze narrowly on individual hardships can inadvertently erase from our view some of the important contextual realities at play that can inform ethical practices. When such realities are eliminated from consideration, it becomes all too easy to universalize our understandings of what is (and what can be) on the basis of individual experiences. Then, the locus of change becomes the individual him or herself, and the burden they bear is only heightened. When we do this - when we base our practices on the notion of some generic individual - that is when I fear we really lose our way, and our ability to "meet" the actual human subjects we encounter through our practice is at stake.

There is great promise in refusing to individualize our understandings of social processes. Reconceptualizing the subject as a non-unitary, nomadic subject highlights our interconnectedness, and reconceptualizing ethics as something that must be engaged with anew in each and every moment heightens our responsibility to the other. I believe such shifts in perception can contribute to the cultivation of prevention practices, community development, and approaches to policy-making that are promising in that they can generate new realities. I agree with Richardson and Reynolds (2012) who insist that if we are not working with an ethic of solidarity and a commitment to justice at the centre of all we do, "we risk replicating dominance and causing harm to our clients and community members” (p. 4). Developing more nuanced understandings of both subjectivity and ethics can help us stay close to this commitment. 
International Journal of Child, Youth and Family Studies (2012) 4.1: 458-478

\section{References}

Abram, D. (1996). The spell of the sensuous. New York: Random House, Inc.

Albanese, P. (2010). Child poverty in Canada. Don Mills, ON: Oxford University Press.

Bostock, J., Plumpton, M., \& Pratt, R. (2009). Domestic violence against women: Understanding social processes and women's experiences. Journal of Community \& Applied Social Psychology, 19(2), 95-110.

Braidotti, R. (2006). Transpositions: On nomadic ethics. Malden, MA: Polity Press.

Buber, M. (1923/1970). I and thou (W. Kraufmann, Trans.). New York: Touchstone.

Butler, J. (2004). Precarious life: The powers of mourning and violence. New York: Verso.

Cameron, J., \& Gibson-Graham, J. K. (2003). Feminising the economy: Metaphors, strategies, politics. Gender, Place, \& Culture, 10(2), 145-157.

Carmody, M. (2003). Sexual ethics and violence prevention. Social and Legal Studies, 12(2), 199-216.

Carmody, M. (2005). Ethical erotics: Reconceptualizing anti-rape education. Sexualities, $8(4), 465-480$.

Carmody, M., \& Carrington, K. (2000). Preventing sexual violence? The Australian and New Zealand Journal of Criminology, 33(3), 341-361.

Carson, L. (2011). Designing a public conversation using the World Café method. Social Alternatives, 30(1), 10-15.

Carson, L., \& Lubensky, R. (2010). Raising expectations of democratic participation: An analysis of the National Human Rights Consultation. University of New South Wales Law Journal, 33(1), 34-59.

Clarke, A. (2005). Situational analysis: Grounded theory after the postmodern turn. Thousand Oaks, CA: SAGE.

Denborough, D. (2008). Collective narrative practice: Responding to individuals, groups, and communities who have experienced trauma. Adelaide, Australia: Dulwich Centre Publications.

Derrida, J. (1995). The gift of death (D. Wills, Trans.). Chicago: University of Chicago Press. 
International Journal of Child, Youth and Family Studies (2012) 4.1: 458-478

Doherty, W., \& Carroll, J. (2007). Families and therapists as citizens: The families and democracy project. In E. Aldarondo (Ed.), Advancing social justice through clinical practice (pp. 223-244). Mahwah, NJ: Lawrence Erlbaum Associates, Publishers.

Farmer, P. (2005). Pathologies of power: Health, human rights, and the new war on the poor. Berkeley, CA: University of California Press.

Foucault, M. (1972). Truth and power. In P. Rabinow (Ed.). (1984). Foucault reader (pp. 5175). New York: Pantheon Books.

Gergen, K. (1994). Realities and relationships: Soundings in social construction. Cambridge, MA: Harvard University Press.

Gergen, K. (1999). An invitation to social construction. Thousand Oaks, CA: SAGE.

Gergen, K. (2009). Relational being: Beyond self and community. New York: Oxford University Press.

Haas, A., Eliason, M., Mays, V., Mathy, R., Cochran, S., D’Augelli, A., et al. (2011). Suicide and suicide risk in lesbian, gay, bisexual, and transgender populations: Review and recommendations. Journal of Homosexuality, 58(1), 10-51.

Healy, S. (2010). Traversing fantasies, activating desires: Economic geography, activist research, and psychoanalytic methodology. The Professional Geography, 62(4), 496506.

Howard, C. (Ed.). (2007). Contested individualization: Debates about contemporary personhood. New York: Palgrave Macmillan.

Kral, M., Wiebe, P., Nisbet, K., Dallas, C., \& Okalik, L. (2009). Canadian Inuit community engagement in suicide prevention. International Journal of Circumpolar Health, 68(3), 292-310.

Kretzmann, J., \& McKnight, J. (1997). A community building workbook from the AssetBased Community Development Institute for Policy Research. Chicago: ACTA Publications.

Kwee, A. (2007). Constructing addiction from experience and context: Peele and Brodsky’s “Love and Addiction” revisited. Sexual Addiction and Compulsivity, 14(3), 221-237.

Lenihan, D. (2012). Rescuing policy: The case for public engagement. Ottawa, ON: Public Policy Forum.

Levinas, E. (1982/2003). On escape [De l'evasion] (B. Bergo, Trans.). Stanford, CA: Stanford University Press. 
International Journal of Child, Youth and Family Studies (2012) 4.1: 458-478

MacArthur, J., Rawana, E., \& Brownlee, K. (2011). Implementation of a strengths-based approach in the practice of child and youth care. Relational Child and Youth Care Practice, 24(3), 6-16.

Malekoff, A. (2010). The use of group work to fight acute external threats to a communitybased organization during harsh economic times. Social Work with Groups, 33(1), 4-22.

McKnight, J. (1995). The careless society: Community and its counterfeits. New York: Basic Books.

Merleau-Ponty, M. (1964). Eye and mind (C. Dallery, Trans.). In J. Edie (Ed), The primacy of perception (pp. 159-190). Evanston, Il: Northwestern University Press.

Mitchell, R. (2011). Human rights and health promotion: A Canada fit for children? International Journal of Child, Youth and Family Studies, 2(3/4), 510-526.

Mohanram, R. (1999). Black body: Women, colonialism, and space. Minneapolis, MN: University of Minnesota Press.

Morris, J., \& White, J. (2010). Risk, responsibility and uncertainty in school-based suicide prevention programs. Social Sciences and Medicine, 71(12), 2187-2194.

Neuhaus, C. (1993). The disease controversy revisited: An ontologic perspective. Journal of Drug Issues, 23(3), n.p.

Newbury, J., \& Hoskins, M. (2008). A meaningful method: Research with girls who use crystal methamphetamine. Child and Youth Care Forum, 37(5/6), 227-240.

Newbury, J., \& Hoskins, M. (2010). Girls are so complicated! Re-imagining addiction support in context. Canadian Journal of Counseling, 44(1), 15-33.

Nollman, G., \& Strasser, H. (2007). Individualization as an interpretive scheme of inequality: Why class and inequality persist. In C. Howard (Ed.), Contested individualization: Debates about contemporary personhood (pp. 81-98). New York: Palgrave Macmillan.

Reynolds, V. (2011). Resisting burnout in feminist activism. Retrieved February 2, 2012 from http://rabble.ca/podcasts/shows/f-word/2011/08/resisting-burnout-feminist-activism

Richardson, C., \& Reynolds, V. (2012). "Here we are, amazingly alive”: Holding ourselves together with an ethic of social justice in community work. International Journal of Child, Youth and Family Studies, 3(1), 1-19.

Rose, D. B. (2008a). On history, trees, and ethical proximity. Postcolonial Studies, 11(2), 157167. 
International Journal of Child, Youth and Family Studies (2012) 4.1: 458-478

Rose, D. B. (2008b). Dreaming ecology: Beyond the between. Religion and Literature, 40(1), 109-122.

Saul, D. (Ed.). (2005). Western Canadian Summit on Methamphetamine: Bringing together practitioners, policy makers, and researchers (Consensus panel report). Vancouver, BC: Vancouver Coastal Health.

Sen, A. (2009). The idea of justice. Cambridge, MA: Harvard University Press.

Taylor, C. (2007). Modern social imaginaries. London: Duke University Press.

Teghtsoonian, K. (2004). Neoliberalism and gender analysis mainstreaming in Aotearoa/New Zealand. Australian Journal of Political Science, 39(2), 267-284.

Todd, S. (2008). Toward an imperfect education: Facing humanity, rethinking cosmopolitanism. Boulder, CO: Paradigm Publishers.

Truan, F. (1993). Addiction as a social construction: A post-empirical view. The Journal of Psychology, 127(5), 489-499.

Winegard, B., \& Winegard, C. J. (2011). The awful revolution: Is neoliberalism a public health risk? Retrieved February 2, 2012 from http://www.opednews.com/articles/3/The-Awful-Revolution-Is-N-by-BenjaminWinegard-110415-653.html

Yeatman, A., Dowsett, G. W., Fine, M., \& Gursansky, D. (2009). Individualization and the delivery of welfare services: Contestation and complexity. New York: Palgrave Macmillan. 